\title{
Impact of Nutrition Education Program Based on Nutritional Assessment of Adolescent in Assiut -Egypt
}

\author{
Faten M. Rabie ${ }^{1} \quad$ Safaa R. Osman ${ }^{2} \quad$ Alyaa H. Abo-Rahma ${ }^{3}$ \\ 1.Public health and community medicine department- faculty of Medicine - Assiut University \\ 2.Lecturer of community health nursing, faculty of nursing, Assiut University \\ 3.Assistant lecturer in Community and Industrial Medicine Department, Faculty of medicine, Al-Azhar \\ University
}

\begin{abstract}
Background: Adolescence is a stage of rapid changing, adequate nutrition is vital for achieving full growth probable, and any disturbance will occur in this stage may lead to various health problems. Aims: to assess the nutritional status and food habits among adolescents and evaluate the impact of the educational program in primary health care sittings. Methodology: quasi-experimental research design was used. Sample size was 350 adolescents (175 intervention group and 175 control group) attending two health facilities (urban and rural) which were selected randomly. Pre and posttest (immediate and late) interview structured questionnaire was used which included socio-demographic data, anthropometric measurements, hemoglobin level, questions regarding knowledge about nutrition and food habits. Results: more than two fifths (44.4\%) of the sample was anemic. The mean body mass index was $21.09 \pm 4.6$. Obesity was significantly more prevalent in female (13.4\%) than male (3.4\%).The knowledge scores of nutritional health was significantly better among adolescents in studied group than control group $(\mathrm{p}$ value $=0.00)$. Also their eating and consumption habits had a slightly improvement. Conclusion: After implementation of the program the Adolescents' knowledge and habits had a remarkable improvement.
\end{abstract}

Keywords: Adolescent, nutrition, eating habits

DOI: $10.7176 / \mathrm{JHMN} / 58-09$

\section{Introduction}

Adolescence is the period of shifting from childhood to reach to adulthood. The World Health Organization (WHO) defines adolescence as "age between 10 and 19 years" [1]. In Egypt, 9.4\% of population aged 10- 14 years while $9.7 \%$ aged $15-19$ years. It is a period of rapid changing which included physiological, sexual, neurological, and behavioral changes. While adolescence is a stage of rapid changing, adequate nutrition is vital for achieving full growth probable, and any disturbance will occur in this stage may lead to various health problems [2].

Many researches revealed that many disturbance, problems and nutritional deficiencies occurred in adolescent stage due to unhealthy eating behaviours and false eating habits. Better nutrition plays a major role in prevention of many non-communicable diseases as obesity, diabetes mellitus, cardiovascular disease ad some types of cancer which may be developed with the long run during adulthood [3]. For this cause, nutrition was a main concern spot for the "Healthy People 2010" and remainder an important objective for Healthy People 2020 [4].

Obesity considered a major public health problem due to its association with many chronic diseases and deterioration health outcomes [5]. It is a multiple, interrelated factors and preventable causes which considered one of causes of early disabilities and impairments[6]. Overweight and Obesity are associated with faulty eating habits as consumption a lot of fast food and soft drink, and over-nutrition. An adolescent overweight is increasing rapidly as shown by the estimated $7 \%$ and $5 \%$ prevalence in Africa and Asia respectively. In Egypt (2014), the prevalence of obesity among male and female aged 10-14 years is $9.9 \%, 8.5 \%$ respectively [7]. In Sharkia Governorate, the prevalence of overweight and obesity was $20 \%$ and $10.7 \%$ respectively among preparatory school adolescents[8].

Anemia is a quiet and worsening health problem mainly iron deficiency anemia which being very common in developed countries and highly prevalent (44\%) in developing country [9]. Adolescents are at high risk of iron deficiency and anaemia due to accelerated increase in requirements for iron during puberty, deprived dietary intake of iron, menstrual losses, and poor dietary habits, frequent of parasitic infection as well as the social and culture attitude of early marriage and adolescent pregnancy [10][11][12].

In Egypt, at Talkha City (2013) a study conducted on related knowledge among Egyptian preparatory school girls, the prevalence of anemia among adolescent girls was $34.0 \%$. Another study conducted in Menoufia governorate at 2015 , revealed that $(30.2 \%)$ of them had iron deficiency anemia and $(9.6 \%)$ of them on anemic [13]. According to Demographic and Health Survey in 2014 reported that overweight and obesity were prevalent among $42.3 \%$ of girls and $30.1 \%$ of boys aged $15-19$ years [14][15].

The nutritional status of adolescents contributes significantly to the health status of the community in which 
they inhabit. Recently, there has been a growing interest in adolescent nutrition in developing countries as a means to improve the health of adolescents [16]. Nutritional assessment is an essential part of a complete health appraisal for them. Nutrition education included many activities, including the assessment of their information, increasing the knowledge on important of foods and healthy behaviors, influencing their attitudes and beliefs, helping them to develop own skills, and motivating them to implement healthy eating practices [13][17].

Community health workers are valuable resources and facilitators of nutrition education. They should encourage the adolescents to improve their nutritional status and motivating them to develop their healthy food practice by improving their nutritional knowledge[17] and discover all new cases [18].

\section{Significant of the study}

Nutrition and diet is a key factor to the growing trend of obesity and a permanent disease associated with the metabolic effects. Diet-related factors are major risk factor non communicable diseases. Nutrition education is an important step toward changing health risk behavior and promoting nutritional status of adolescents which will decrease risk of nutritional diseases.

\section{Aim of the study}

Is to assess the nutritional status and food habits among adolescents and evaluate the impact of the educational program in primary health care sittings.

\section{Data and methods:}

Study design:

Quasi-experimental research design was used.

\section{Study setting:}

The sitting was selected in two stages:

Stage I: Two districts were randomly selected from eleven districts in Assiut Governorate.

Stage II: One health facility (PHC) from each district was selected randomly (urban and rural).

\section{Sample size calculation and technique:}

Sample size was 302 which increased to 350 to prevent drop out. It calculated using EPI info 7 software with $97 \%$ confidence level and power $80 \%$ of the test by using the prevalence of overweight in Sharkia Governorate, Egypt which represented 20\% [8]. Adolescents who came to the PHC centers for utilizing any PHC services and agree to participate in the study were included.

Technical design:

Tools of the study:

Interview questionnaire was designed according to evidence - based questionnaires which divided into:

Part (1): It included socio-demographic data as name, age, sex, education, parents' work and education, family income, and marital status.

Part (2): Anthropometric Measurements and hemoglobin level

Anthropometric Measurements: Height and weight were measured to all adolescents in stage (1). According to the World Health Organization's criteria [19][20], Body mass index (BMI) was calculated using the following equation:

\section{BMI = weight in kilograms / (height in meter $)^{2}$. It was classified as: \\ 1) Underweight: Participants with a BMI of $<18.5 \mathrm{~kg} / \mathrm{m} 2$. \\ 2) Normal weight, Participants with a BMI of $18.5-24.99 \mathrm{~kg} / \mathrm{m} 2$. \\ 3) Overweight; Participants with a BMI of 25 to $<30 \mathrm{~kg} / \mathrm{m} 2$. \\ 4) Obese, Participants with a BMI of $\geq 30 \mathrm{gfd} \mathrm{kg} / \mathrm{m} 2$.}

Hemoglobin level: by disinfected technique, capillary blood drops were collected from all adolescents using a finger prick method. The first drop of blood was discarded away using alcohol sterile wipes, and the next drop was placed into the Hemocue curvette for immediate testing of haemoglobin.

Part (3): it included the nutritional habits of the adolescents and assessed their knowledge about nutrition and some disorders as anemia and obesity (causes, hazards and prevention) (pre, post and follow up test). Questions were scored as 1 marks for correct answer and 0 marks for wrong or no answer or refusing to answer.

Nutritional habits and knowledge were assessed and evaluated immediately. Sample divided into two groups (Intervention and control group). Health education given to the intervention group who divided into small groups (3-5 adolescents) followed by immediate post test for intervention group. After that all adolescent came back after 3 months for follow up test. 


\section{Part (4): The educational program}

The educational program is a behavioral prevention intervention based on Guidelines for Adolescent Preventive Services (GAP). It aimed to improve the adolescents' knowledge and habits. The program had been strengthened by a colorful educational booklet and posters. Each respondent from the adolescents received colorful educational booklet as a gift to attract the adolescents to the booklet content.

Prior to application, the questionnaire reliability was reviewed by a team, one specialist in the field of Community Health Nursing- faculty of nursing and two specialists in Public health Medicine at Assiut University to assess the relevance and framing of the questions as well as accuracy of the Arabic translation.

\section{Methodology:}

I- Preparing stage:

Investigators designed an educational plan to improve adolescents' knowledge and modify their food habits.

II- Regulating stage:

This stage involved the organization for achieving the program as: preparing the place of lecture, meeting, and colorful educational booklet.

\section{III- Implementation stage:}

Health education given to the intervention group who divided into small groups (3-5 adolescents) followed by immediate post test for intervention group. After that all adolescent came back after 3 months for follow up test. Health education session takes one hour to complete the program content.

\section{IV- Evaluation stage:}

The evaluation was done through posttest which done immediately after implementing and completing the content to assess their knowledge and food habits for intervention group, and follow up test for all sample (intervention and control group)

\section{Data collection (Working field):}

Data collected from July, 2017, to November, 2017.At the initial visit all adolescents were completed the pre test and measured their weight, height, and hemoglobin level. The sample was divided into two groups 175 were chosen randomly for receiving the health educational program (intervention group) and immediate post intervention questionnaire was administered to evaluate the immediate impact of the educational program. The other 175 was considered as control group. The whole adolescents receiving the intervention returned after 3 months to evaluate the long term effect of health education program.

\section{Administrative phase:}

An official letter approval was obtained from the Dean of the Faculty of medicine, Assiut University and directed to the directorate of health to complete the study. The letter included a permission to carry out the study.

\section{Pilot study:}

The questionnaire was pilot-tested on 50 adolescents to ensure that the questionnaire was understandable to all studied sample. The questionnaire required about 20-30 minutes to complete. The aim of this study was to test the clarity of the tools and to determine the required time to complete the questionnaire.

\section{Data management:}

The questionnaire was revised, coded and cleaned and checked for missing and non-logic skip pattern.

Descriptive statistics were used to illustrate respondents 'demographic characteristics. Categorical variables were measured as percentages while continuous variables were expressed as mean \pm standard deviation. The Shapiro test was applied to determine the nature of distribution.

Mann-Whitney U test and independent T-test were performed to compare binary variables with knowledge. Kruskal-Wallis test was used to compare the knowledge scores with multiple variables. Wilcoxon test used to evaluate the effect of health education program by difference between pre and post intervention level of knowledge. McNemar's test was used to show in details the success of our interventional educational program. Chi-square tests and Fisher Exact test were used to investigate possible differences in the studied sample.

\section{Ethical considerations}

- Study suggestion was confirmed from ethical committee in the Faculty of medicine, Assiut University.

- No danger was found during implementation of the study.

- This study was following general moral concepts in clinical study.

- Written consent gained from all adolescents or their parents who were willing to share in the study after clarifying the reality and goal of the study.

- $\quad$ Privacy and anonymity was confirmed. 
- Research participant had the choice to reject to join or dropped out from the research at any time they want and in the absence of any reason.

- Study participant singularity was taken in consideration during data collection.

\section{Results}

The studied sample included 350 adolescents from rural and urban health facilities. About two thirds (66.3\%) of the sample was female. According to their ages, 58.5\% ranged from 10- 13 years, 26.5\% from 14- 16 years and finally $14.5 \%$ their ages ranged from $17-19$ years. The vast majority of the sample $(97.7 \%)$ were educated, $24.3 \%$ of them had an average family monthly income from 1000-5000 pound. According to parents education, more than half $(57.7 \%)$ of mothers were illiterate and less than half $(49.1 \%)$ of fathers were illiterate.

Table 1: Distribution of adolescents according to their hemoglobin status and body mass index at PHC Units in Assiut Governorate.

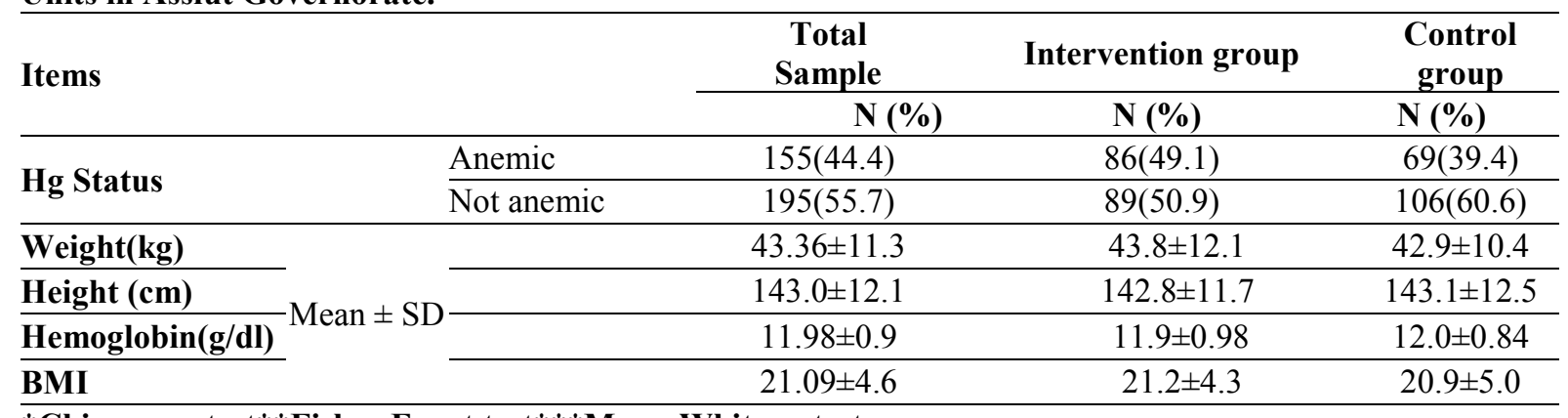

\section{*Chi square test**Fisher Exact test***Mann Whitney test}

According to hemoglobin status table (1) showed that more than two fifths $(44.4 \%)$ of the sample was anemic. The mean of weight, height and BMI for total sample were $(43.36 \pm 11.3,143.0 \pm 12.1$ and $21.09 \pm 4.6$ respectively).

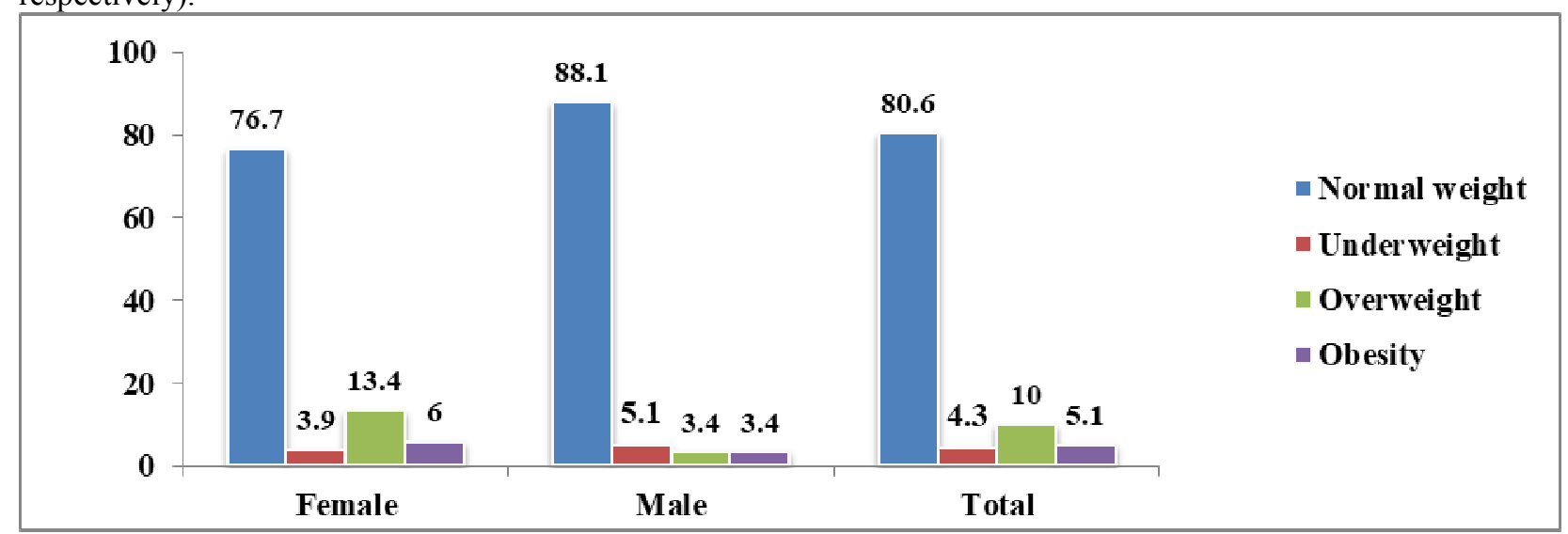

Figure (1): Prevalence of underweight, Overweight and Obesity among Adolescents at PHC sittings in Assiut Governorate.

Figure (1) shows the prevalence of overweight and obesity in adolescents. Underweight presented in 4.3\%of the studied sample. Overweight was significantly (P-value=0.002) more prevalent in female $(13.4 \%)$ than male (3.4\%).according to the prevalence of obesity, it presented (5.1\%) in the entire sample. 
Table 2: Determinant of overweight and obesity among adolescents at PHC sittings in Assiut Governorate

\begin{tabular}{|c|c|c|c|c|}
\hline \multirow[t]{2}{*}{ Factors } & \multirow[t]{2}{*}{ P-value* } & \multirow[t]{2}{*}{ Odds Ratio } & \multicolumn{2}{|c|}{ 95\% C.I } \\
\hline & & & Lower & Upper \\
\hline \multicolumn{5}{|l|}{ Gender } \\
\hline Male & \multicolumn{4}{|c|}{$\operatorname{Ref}^{* *}$} \\
\hline Female & .008 & 3.179 & 1.351 & 7.479 \\
\hline \multicolumn{5}{|l|}{ Type of Place } \\
\hline Rural & Ref & & & \\
\hline Urban & .181 & .593 & .276 & 1.275 \\
\hline \multicolumn{5}{|l|}{ Adolescent's Education } \\
\hline Illiterate & & Ref** & & \\
\hline Primary & .247 & .578 & .228 & 1.463 \\
\hline Preparatory & .848 & .884 & .251 & 3.109 \\
\hline Secondary and university & .853 & .831 & .118 & 5.848 \\
\hline \multicolumn{5}{|l|}{ Work Status } \\
\hline Working & & Ref** & & \\
\hline Not working & .795 & .817 & .179 & 3.737 \\
\hline \multicolumn{5}{|l|}{ Age } \\
\hline \multicolumn{5}{|l|}{ Age (10-13) } \\
\hline Age (14-16) & .114 & 2.208 & .827 & 5.895 \\
\hline Age (17-19) & .455 & 1.642 & .447 & 6.032 \\
\hline \multicolumn{5}{|l|}{ Type of Family } \\
\hline Nuclear & & Ref** & & \\
\hline Extended Family & .969 & .985 & .452 & 2.146 \\
\hline \multicolumn{5}{|l|}{ Mother Education } \\
\hline Illiterate & $\mathrm{REI}$ & & & \\
\hline Primary & .735 & 1.393 & .204 & 9.520 \\
\hline Secondary and University & .120 & 2.050 & .830 & 5.064 \\
\hline Read and write only & .286 & 1.625 & .667 & 3.961 \\
\hline Preparatory & .875 & .881 & .184 & 4.223 \\
\hline \multicolumn{5}{|l|}{ Father Education } \\
\hline Illiterate & REF & & & \\
\hline Primary & .870 & 1.115 & .303 & 4.101 \\
\hline Secondary and University & .605 & .786 & .316 & 1.955 \\
\hline Read and write only & .267 & 1.637 & .686 & 3.904 \\
\hline Preparatory & .010 & 5.700 & 1.514 & 21.463 \\
\hline *Binary & regressio & by & enter & method \\
\hline
\end{tabular}

** Reference group

Table 2 showed the determinant of being overweight and/or obese. Females were 3 times than males in being overweight /obese. Gender was the only factor that showed significance as a determinant for overweight and obesity.

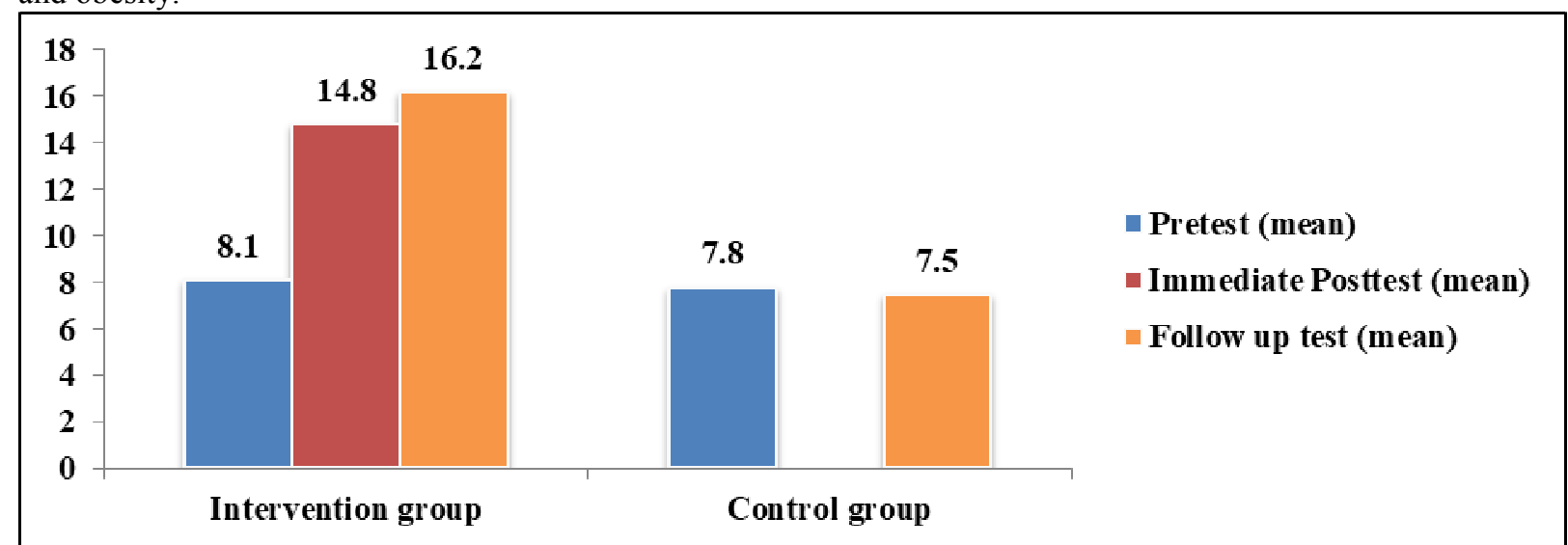

Figure (2): Effect of Health Education Intervention on Adolescent nutritional Knowledge (pre, Immediate and Late Evaluation) at PHC sittings in Assiut Governorate. 
Figure (2) revealed that there was a highly significant improvement of knowledge ( $\mathrm{p}$ value $=0.00)$ among intervention group than controlled group in (pre, immediate and late intervention) $(8.1 \%, 14.8 \%$ and 16.2$)$ respectively.

Table 3: Relationship of nutrition Knowledge score with selected demographic characteristics among adolescents at PHC sittings in Assiut Governorate.

\begin{tabular}{|c|c|c|c|}
\hline Demographic data & & Mean Rank & P-value \\
\hline \multirow{3}{*}{ Age } & $10-13$ & 167.8 & \multirow{3}{*}{$0.21 * *$} \\
\hline & 14-16 & 183.4 & \\
\hline & $17-19$ & 191.5 & \\
\hline \multirow{2}{*}{ Sex } & Male & 190.7 & \multirow{2}{*}{$0.04 *$} \\
\hline & Female & 167.5 & \\
\hline \multirow{2}{*}{ Residence } & Urban & 188.7 & \multirow{2}{*}{$0.01 *$} \\
\hline & Rural & 162.3 & \\
\hline \multirow{4}{*}{ Education } & Illiterate & 145.5 & \multirow{4}{*}{$0.059 * *$} \\
\hline & Primary & 163.7 & \\
\hline & Preparatory & 177.8 & \\
\hline & Secondary and university & 201.7 & \\
\hline \multirow{2}{*}{ Work status } & Work & 187.8 & \multirow{2}{*}{$0.54^{*}$} \\
\hline & Not work & 174.4 & \\
\hline \multicolumn{4}{|c|}{$\mathbf{N}=\mathbf{3 5 0}$} \\
\hline
\end{tabular}

*Using Mann-Whitnny test for non-parametric data.

**Using Kruskalis-Wallis test for non-parametric data

Table (3) showed the relationship of nutrition Knowledge score with selected demographic characteristics among adolescents at PHC sittings in Assiut Governorate. It revealed that there was a significant relationship ( $p$ value $=0.04,0.01$ respectively) between nutrition Knowledge score and demographic characteristics (sex and eduction)

Table 4: Effects of Health Education Intervention on Adolescents' consumption and eating habits

\begin{tabular}{|c|c|c|c|c|c|c|}
\hline \multirow{2}{*}{ Variables } & \multicolumn{2}{|c|}{ Intervention group } & \multirow{2}{*}{$\begin{array}{c}\text { McNemar's } \\
\text { chi square } \\
\text { tes } \\
\text { p-value }\end{array}$} & \multicolumn{2}{|c|}{ Control group } & \multirow{2}{*}{$\begin{array}{c}\text { McNemar's } \\
\text { chi square } \\
\text { test } \\
\text { p-value }\end{array}$} \\
\hline & $\begin{array}{c}\text { Pre-test } \\
n=175 \\
(\%)\end{array}$ & $\begin{array}{c}\text { Post test } \\
\mathrm{N}=175 \\
(\%) \\
\end{array}$ & & $\begin{array}{c}\text { Pre-test } \\
\text { N=175 } \\
(\%) \\
\end{array}$ & $\begin{array}{c}\text { Post test } \\
\mathrm{N}=174 \\
(\%) \\
\end{array}$ & \\
\hline \multicolumn{7}{|l|}{ Consumption habits * } \\
\hline Choose a low-fat diet and cholesterol & $116(66.3)$ & $119(68.4)$ & 0.45 & $95(54.3)$ & $105(60.0)$ & 0.01 \\
\hline Choose food that contains few sugars & $97(55.4)$ & $96(55.2)$ & 1.00 & $93(53.1)$ & $99(56.6)$ & 0.21 \\
\hline Eat enough bread, rice, or pasta daily & $127(72.6)$ & $129(74.1)$ & 0.25 & $133(76.0)$ & $131(74.9)$ & 0.50 \\
\hline Eat 2: 4 servings of fruit daily & $120(68.6)$ & $122(70.1)$ & 0.25 & $107(61.1)$ & $115(65.7)$ & 0.07 \\
\hline Eat 3: 5 servings of vegetables daily & $109(62.3)$ & $111(63.8)$ & 0.37 & $117(66.9)$ & $119(68.0)$ & 0.77 \\
\hline $\begin{array}{l}\text { Eat 2: } 3 \text { servings of yogurt and cheese } \\
\text { daily }\end{array}$ & $67(38.3)$ & $82(47.1)$ & 0.00 & $100(57.1)$ & $105(60.0)$ & 0.180 \\
\hline $\begin{array}{l}\text { Eat 2: } 3 \text { servings of meat, chicks, fish } \\
\text { and eggs daily }\end{array}$ & $125(71.4)$ & $130(74.7)$ & 0.03 & $113(64.6)$ & $113(64.6)$ & 1.00 \\
\hline \multicolumn{7}{|l|}{ Eating habits * } \\
\hline Drink water while eating & $139(79.4)$ & $137(78.7)$ & 1.00 & $137(78.3)$ & $136(77.7)$ & 1.00 \\
\hline Drink tea immediately after eating & $65(37.1)$ & $42(24.1)$ & 0.01 & $39(22.3)$ & $38(21.8)$ & 1.00 \\
\hline Drink plenty of soft drinks & $46(26.3)$ & $50(28.7)$ & 0.12 & $53(30.3)$ & $46(26.3)$ & 0.06 \\
\hline Didn't eat breakfast & $32(18.3)$ & $27(15.5)$ & 0.21 & $25(14.3)$ & $20(11.4)$ & 0.18 \\
\hline Consuming a lot of salt in the food & $39(22.3)$ & $38(21.8)$ & 1.00 & $42(24.0)$ & $36(20.6)$ & 0.10 \\
\hline Eating in front of the television & $108(61.7)$ & $101(58.0)$ & 0.03 & $89(50.9)$ & $78(44.6)$ & 0.007 \\
\hline Healthy vegetables and fruits snack & $37(21.1)$ & $65(37.1)$ & 0.00 & $43(24.9)$ & $36(20.6)$ & 0.11 \\
\hline Used healthy oil & $30(17.1)$ & $31(17.8)$ & 0.9 & $28(16.0)$ & $30(17.1)$ & 0.9 \\
\hline
\end{tabular}

\section{* correct response}

According to consumption habits, table (4) showed that adolescents in studied group adhere to low fat diet, eat enough bread, fruits, vegetables and yogurt after educational program $(68.4 \%, 74.1,70.1 \%, 63.8 \%$, and $47.1 \%$ respectively). Also, it revealed that their eating habits improved in drinking tea immediately after eating which decreased from $(37.1 \%)$ to $(24.1 \%)$, Eating in front of the television from $(61.7 \%)$ to $(58.0 \%)$, and eating healthy vegetables and fruits snack from $(21.1 \%)$ to $(37.1 \%)$. 


\section{Discussion}

Better nutrition plays a major role in prevention of many non-communicable diseases as obesity, diabetes mellitus, cardiovascular disease ad some types of cancer which may be developed with the long run during adulthood [3]. For this cause, nutrition was a main concern spot for the "Healthy People 2010" and remainder an important objective for Healthy People 2020 [4].

One of the important results of this study was that more than two fifths of the adolescents were anemic. This finding resembles the result produced by an Egyptian study in Upper Egypt among adolescents which was $40 \%$ [21] and in Ghana, it found that the prevalence of anaemia was 49.5\% among adolescents [11]. Another study done on Iron Deficiency Anemia in Adolescent Girls in Rural Upper Egypt at 2015, revealed that 30.2\% of them had anemia[13].

In a study conducted under title "Anemia and iron deficiency among school adolescents: burden, severity, and determinant factors in southwest Ethiopia" The overall prevalence of anemia was more than fifteen percent which contracted with this study[22]. Also it didn't compatible with a study conducted among Korean adolescents which revealed that the overall prevalence of iron deficiency was $3.1 \%$, with prevalence of $0.5 \%$ among boys and $6.2 \%$ among girls [23].

This result may be due to unhealthy eating habits of the studied sample. Also, all studied sample taken from health care sitting who may be sick persons. Also, it may due to the differences of culture and eating habits among adolescents in different countries.

According to $\mathrm{BMI}$, it found that mean $\pm \mathrm{SD}$ was $21.09 \pm 4.6$. similar finding demonstrated in a study conducted in Iran which showed that the mean BMI was 22.01 \pm 3.57 [24]. Obesity and overweight prevalence was $15.1 \%$ demonstrating the existence of the burden of overweight and obesity among adolescents. The current finding inconsistent with the results of many studies conducted in 6 African countries as Benin, Djibouti, Ghana, Malawi, Mauritania, and Morocco $(0.6 \%, 5.2 \%, 1.0 \%, 0.8 \%, 3.4 \%$ and 3.6\% respectively).

The higher overweight and obesity prevalence in Egyptian youth may be indicative of nutrition transition occurring in the context of rapid urbanization and related to culture and diet. Regional differences in factors contributing to weight status is also evidenced by the presence of heterogeneity in some risk factors possibly related to varying urban vs. rural population distribution[7].

The present study demonstrates that health knowledge and attitude regarding adolescents' health was unsatisfying before program implementation. After implementation, there was a significant increase in knowledge among the adolescents in the studied group than the control group. Similar findings demonstrated the role of health education in positive changing adolescents' knowledge and attitude as the study that was conducted in Brazil and reported improvements in health practice as decreasing consumption of sweets, in a group of 150 adolescent, who participated in the health education program [25]. Also, similar finding found in a study conducted in South Italy and Palestine [16][26].

Role of health education in improvement the population health is well established fact and the link between education and health was proven on evidence based basis [27]

This study showed that the adolescents in intervention group adhere to low fat diet, eat enough bread, fruits, vegetables and yogurt after educational program, also, it revealed that their eating habits improved in drinking tea immediately after eating, eating in front of the television and eating healthy vegetables and fruits snack. These results are in agreement with the results of Samantha et al that found that nutrition education improved the nutritional habits among the studied group (28).

Conclusion: In the light of the study results, it can be concluded that Adolescents' knowledge and habits were mostly poor. After implementation of the program remarkable improvement were achieved in adolescents' knowledge.

-Comprehensive health education for adolescent should be given by using various educational media through lectures, workshops, face to face interview and attractive media.

-Periodic screening of adolescents for anemia and obesity. The strategies must be based on the individual, community and physician's efforts in PHC centers.

- Further researches; based on a larger sample size, are needed to assess and improve the adolescents' knowledge and eating habits.

\section{Acknowledgments:}

The researchers would like to thank all participated adolescents, doctors and nurses in the primary health care settings.

\section{Funding:}

World Health Organization under Research in Priority Areas of Public Health Grant Scheme (RPPH)

Competing interests: None declared. 


\section{References}

[1] J. K. Das et al., "Nutrition in adolescents: physiology, metabolism, and nutritional needs," Ann. N. Y. Acad. Sci., vol. 1393, no. 1, pp. 21-33, 2017.

[2] G. Sireesha, N. Rajani, and V. Bindu, "Teenage girls ' knowledge attitude and practices on nutrition," vol. 3, no. 2, pp. 491-494, 2017.

[3] K. Kromeyer-hauschild et al., "Current Guidelines for Obesity Prevention in Childhood and Adolescence,” Euroupean J. Obes., vol. 11, pp. 263-276, 2018.

[4] U. S. D. of H. and H. Services, "Healthy People 2020," 2013.

[5] K. Widhalm, "Prevention of Obesity in Childhood and Adolescence," Euroupean J. Obes., vol. 11, pp. 232-233, 2018.

[6] F. H. Majid Zamani, Mohammad Nasr Esfahani, Ibrahim Joumaa, "Accuracy of Real time Intratracheal Bedside Ultrasonography and Waveform Capnography for Confirmation of Intubation in Multiple Trauma Patients," Adv. Biomed. Res., pp. 1-6, 2018.

[7] T. Manyanga, H. El-Sayed, D. T. Doku, and J. R. Randall, “1. Manyanga T, El-Sayed H, Doku DT, Randall JR. The prevalence of underweight, overweight, obesity and associated risk factors among school-going adolescents in seven African countries. BMC Public Health. 2014;14:887. doi:10.1186/1471-2458-14-887.The prev," BMC Public Health, vol. 14, p. 887, 2014.

[8] M. A. Talat and E. El, "Prevalence of overweight and obesity among preparatory school adolescents in Urban Sharkia,” Egypt. Pediatr. Assoc. Gaz., vol. 64, no. 1, pp. 20-25, 2016.

[9] T. Shesha, I. Chaluvaraj, and P. T. Satyanarayana, "Change in Knowledge , Attitude and Practice Regarding Anaemia among High School Girls in Rural Bangalore : An Health Educational Interventional Study," Natl. J. Community Med., vol. 9, no. 5, pp. 358-362, 2018.

[10] WHO, "PREVENTION OF IRON DEFICIENCY ANAEMIA IN ADOLESCENTS ROLE OF WEEKLY IRON,” 2011.

[11] E. Aurino et al., "Agro - ecological zone and farm diversity are factors associated with haemoglobin and anaemia among rural school - aged children and adolescents in Ghana," no. June, pp. 1-11, 2018.

[12] Y. Melaku, A. Dirar, G. T. Feyissa, and D. Tamiru, "Optimal dietary practices and nutritional knowledge of school adolescent girls in Jimma Town, South West Ethiopia," Int. J. Adolesc. Youth, vol. 23, no. 3, pp. 299-307, 2018.

[13] N. Hussein, M. Mohamed, and A. Ouda, "Life style risk factors of Iron deficiency Anemia among adolescents ' girls," no. 10, 2018.

[14] S. M. Sabbour, W. M. Hussein, G. Essam, and E. Amin, "Fruit and Vegetable Consumption among Medical Students in an Egyptian University: Knowledge, Practice, and Attitude towards Accessible Healthy Food," vol. 36, no. 1, pp. 75-93, 2018.

[15] demographic and health survey, "Egypt Demographic and Health Survey," 2014.

[16] G. Grosso, A. Mistretta, G. Turconi, H. Cena, C. Roggi, and F. Galvano, "Nutrition knowledge and other determinants of food intake and lifestyle habits in children and young adolescents living in a rural area of Sicily, South Italy," Public Health Nutr., vol. 16, no. 10, pp. 1827-1836, 2013.

[17] S. I. A. Abd El-Rahman, S. A. Hassan, and S. I. El-Bastawesy, "Assessment of Nutritional Status among Preparatory School Girls in Talkha City," Egypt. J. Hosp. Med., vol. 52, no. 52, pp. 493-505, 2013.

[18] J. Broad and M. Wallace, "Commentary Nutrition and public health in medical education in the UK: re fl ections and next steps," vol. 21, no. 13, pp. 2523-2525, 2018.

[19] W H O, "OBESITY : PREVENTING AND MANAGING THE GLOBAL EPIDEMIC Report of a," 2000.

[20] F. Q. Nuttall, “Body Mass Index,” Nutr. to day, vol. 50, no. 3, pp. 117-128, 2015.

[21] S. O. Mousa, "Cognitive Function and School Achievement in Adolescent Egyptian Girls with Iron Deficiency and Iron Deficiency Anaemia,” pp. 289-294, 2016.

[22] D. Press, "Anemia and iron deficiency among school adolescents : burden , severity , and determinant factors in southwest Ethiopia," pp. 189-196, 2015.

[23] H. W. Chueh, D. Ph, Y. C. Choi, J. H. Shin, J. H. Yoo, and D. Ph, "Family History as a Risk Factor for Iron Deficiency Anemia among Korean Adolescents: Data from the Fifth Korea National Health and Nutrition Examination Survey ( KNHANES )," Clin. Pediatr. Hematol., vol. 25, no. 1, pp. 31-37, 2018.

[24] P. Gude et al., "Original Article," vol. 4, no. 4, pp. 915-920, 2016.

[25] E. A. Nery, "Health education with adolescents: analysis of knowledge acquisition on health topics," vol. 19, no. 3, pp. 484-490, 2015.

[26] F. A. W. Ghrayeb, M. A. Rusli, A. Al Rifai, and M. I. Ismail, "Effectiveness of nutrition education intervention among high school students in Tarqumia, Palestine," Pakistan J. Nutr., vol. 12, no. 8, pp. 787-792, 2013.

[27] D. P. Baker, J. Leon, E. G. S. Greenaway, J. Collins, and M. Movit, “NIH Public Access,” vol. 37, no. 2, 
2011.

[28] Samantha Partida, Autumn Marshall, Ruth Henry, Jeremy Townsend and Ann Toy, Attitudes toward Nutrition and Dietary Habits and Effectiveness of Nutrition Education in Active Adolescents in a Private School Setting: A Pilot Study, 2018, The Egyptian Journal of Community Medicine Vol. 36 No. 1 